\section{Relationship between type 2 diabetes and pancreatic cancer}

\author{
M. Temel Yilmaz, ${ }^{1-3}$ Ali Osman Gürol ${ }^{1,3}$ \\ ${ }^{1}$ Diabetes Application and Research \\ Center (DIYAM), Istanbul University, \\ Sehremini; ${ }^{2}$ Department of Internal \\ Medicine, Endocrinology and Metabolic \\ Diseases Division, Istanbul Medicine \\ Faculty, Istanbul University, Capa; \\ ${ }^{3}$ Department of Immunology, Aziz \\ Sancar Institute of Experimental \\ Medicine, Istanbul University, \\ Sehremini, Istanbul, Turkey
}

\begin{abstract}
Diabetes mellitus and cancer are conditions that constitute a serious problem for the health of the world's population, and their co-existence in the same person is becoming increasingly common. Glucose metabolism and the presence of insulin in inflammatory situations appear to be the main factors driving this association, where hyperinsulinemia has been shown to contribute to an increase in risk of association between type 2 diabetes and cancer. Therefore, administering lower levels of exogenously administered insulin to patients with type 1 diabetes would decrease their risk of developing cancer when compared to patients with type 2 diabetes. The results from animal experiments seem promising in terms of pharmacological treatment.
\end{abstract}

\section{Introduction}

The pancreas is a glandular organ that lies in the upper abdomen behind the stomach. ${ }^{1}$ It has two functional cellular compartments: endocrine and exocrine. ${ }^{2,3}$ The endocrine pancreas (islets of Langerhans) makes and secretes hormones (insulin, glucagon, somatostatin, pancreatic polypeptide and ghrelin) into the blood to control energy metabolism and storage throughout the body. The exocrine pancreas as a part of the gastrointestinal system makes and secretes digestive enzymes (proteases, pancreatic lipase and amylase) into the intestine. ${ }^{1}$ It contains acinar, ductal and centroacinar cells. Pancreatic cord, an undifferentiated pancreatic trunk epithelium, is present in the early stages of embryonic development and these cord cells proliferate and, differentiate into endocrine and exocrine lineages. Ductal cells remain quiescent in the adult pancreas and constitute the flow pathway of enzymes that are secreted from the acinar cells which are the most abundant cells in the pancreas, and responsible for the secretion of digestive enzymes. ${ }^{2,3}$

The acinar cells can be transformed into ductal or ductal-like cells because of their intrinsic plasticity. This condition is called acinar-ductal metaplasia playing a role in the process of acute-chronic pancreatitis, and constitutes the first step in the formation of pancreatic intraepithelial neoplasia. ${ }^{2,3}$ Malignant neoplasms of the pancreas are classified according to their cellular characteristics: ductal, acinar and neuroendocrine. Macroscopic images show whether these tumors are solid or cystic. The vast majority of pancreatic cancers (PCs) are infiltrating ductal adenocarcinomas. ${ }^{2}$ They arise from various types of non-invasive precursor lesions. Three types of precursor lesions are found: intraductal papillary mucinous neoplasms (IPMNs), mucinous cystic neoplasms (MCNs) and pancreatic intraepithelial neoplasia (PanIN). These lesions are the precursors of invasive cancer. ${ }^{2,4}$ Cytopathologically, precursor lesions are graded as acinar-to-ductal metaplasia (ADM) and PanIN. PanIN is also divided into three levels: PanIN1, PanIN2 and PanIN3. ${ }^{5,6}$ An important feature of $\mathrm{PC}$ is the presence of a dense stroma, called the desmoplastic reaction, consisting of cellular and fibrillar elements. The pancreatic stellate cells play a key role in the formation of desmoplastic reaction by activating transforming growth factor-1 (TGF-1), fibroblast growth factor (FGF) and platelet-derived growth factor (PDGF), and differentiation into myofibroblasts secreting collagen and other components of the extracellular matrix. Pancreatic stellate cells have been found to play a key role in pancreatic tumor metabolism by secreting non-essential amino acids such as alanine, which displaces glucose and glutamine-derived carbon involved in tricarboxylic acid (TCA) cycle. In this way the dependence of the tumor from glucose and from the nutritive derivatives of the serum becomes reduced. ${ }^{2,7}$

The prevalence of diabetes mellitus (DM) and cancer are increasing worldwide. ${ }^{8} \mathrm{DM}$ is an important and serious problem for global public health. ${ }^{9}$ Its prevalence is increasing worldwide, where 366 million people were diagnosed with diabetes in 2011 and it is estimated to reach 552 million by $2030 .^{10,11} \mathrm{DM}$ is characterized as poorly regulated glucose homeostasis due to defective insulin secretion resulting in large fluctuations between chronic hyperglycemia and hyperinsulinemia, due to disregolaments in the metabolism of carbohydrates, fats and proteins. ${ }^{12}$ Diabetes is caused by dysfunction or death of beta-cells
Correspondence: Ali Osman Gürol, Diabetes Application and Research Center (DIYAM), Aziz Sancar Institute of Experimental Medicine Building, Istanbul University, Sehremini, Istanbul, Turkey.

Tel.: +90.544.794.3144 - Fax: +90.212.532.4171 E-mail: ogurol@yahoo.com

Acknowledgments: the authors would like to thank Miss Nurin Ludin, MSc for her assistance during the editing process.

Key words: Pancreas; Cancer; Diabetes.

Contributions: MTY provided intellectual concept of the manuscript; AOG designed and wrote the manuscript.

Conflict of interest: the authors declare no potential conflict of interest.

Funding: none

Received for publication: 17 August 2017. Revision received: 5 September 2018. Accepted for publication: 28 September 2018.

This work is licensed under a Creative Commons Attribution 4.0 License (by-nc 4.0).

(C)Copyright M.T. Yilmaz and A.O. Gürol, 2018 Licensee PAGEPress, Italy

Translational Medicine Reports 2018; 2:7002 doi:10.4081/tmr.7002

resulting in defects in glucose homeostasis. The two most common forms of diabetes include type 1 diabetes (T1D) and type 2 diabetes (T2D). T1D is characterized by deficiency in insulin secretion as a result of autoimmune destruction of beta-cells. T2D consists of hyperglycemia combined to insulin resistance (IR), insufficient insulin secretion, and incorrect glucagon secretion. ${ }^{10,13}$

Previously, it has been shown that the $\mathrm{DM}$ is among the risk factors for PC. ${ }^{14} \mathrm{PC}$ is a malignant tumor of the pancreas. Although the defects in the ductal epithelial cells are the most potent contributors to the developement of PC, it has been shown that the endocrine portion is often involved in the developement of PC for its interaction with the exocrine. ${ }^{15}$

Pancreatic ductal adenocarcinoma (PDAC) accounts for $90 \%$ of malignant pancreatic neoplasms. ${ }^{2}$ In 2015, there were 367,000 new cases in the world and 359,000 deaths occurred in the same year. In developed countries, PDAC, which is the fourth cause of death today, can take second place in cancer-related deaths within the next 20 years if appropriate treatments cannot be developed. ${ }^{2,16}$ Despite much research, the 5-year survival rate in PDAC 
is still below 7\%. ${ }^{17,18}$ The risk of developing $\mathrm{PC}$ in smokers is three times higher than in non-smokers and $5-10 \%$ of patients have familial history. ${ }^{2}$ Together with age, chronic pancreatitis and T2D, the disease progresses painlessly. ${ }^{19}$ Most patients remain asymptomatic until complications with distant metastases. ${ }^{5}$

\section{Association of type 2 diabetes and pancreatic cancer}

Pancreatic cancer (PC) is usually asymptomatic in early periods. Since there is no accurate screening biomarker, population-based PC screening is not currently available. ${ }^{20}$ Body Mass Index (BMI- $\mathrm{kg} / \mathrm{m}^{2}$ ) with modifiable risk factors, smoking and obesity, height and waist-to-hip ratio should also be considered as risk factors. ${ }^{20-24}$

There are also metabolic conditions in which obesity is associated: hypercholesterolemia, hyperglycemia, IR and T2D. Cholesterol intake, high glucose levels, hyperinsulinemia and T2D status have all been determined as potential pancreatic cancer risk factors..$^{20,25-29}$

Type 2 diabetes mellitus (T2D) is associated with hyperglycemia and a risk to develop PDAC. Cancer stem cells (CSCs) are crucial for initiation and maintenance of tumors, and acquisition of CSC-features is linked to epithelial-mesenchymal-transition (EMT). Hyperglycemia might promote the acquisition of mesenchymal and CSC-properties in premalignant and malignant pancreatic ductal epithelial cells (PDEC) by activating transforming growth factor- $\beta$ (TGF- $\beta$ ) signaling and explain how T2D facilitates pancreatic tumorigenesis. ${ }^{30}$

Majority of patients with PC exhibit altered glucose metabolism. ${ }^{13}$ Metabolic and inflammatory factors correlated with long-term insulin resistance may play a role in tumorigenesis and its progression. ${ }^{9}$ The tumor formation requires a certain environment to be realized. High levels of insulin production commonly occuring in the context of T2D generates a suitable environment causing cell growth and proliferation of blood vessels in the pancreas. ${ }^{15}$ Due to the lower exposure to insulin with only exogenous administration of insulin, patients with T1D appear to be at lower risk for PC. ${ }^{31} \mathrm{DM}$ has been shown to be both a risk factor and a consequence of PC. . $2,33^{2}$

The reciprocity between $\mathrm{T} 2 \mathrm{D}$ and $\mathrm{PC}$ is not yet certain, ${ }^{13,34}$ but it has been shown that the progression of the cancerous state is affected by T2D that contributes to enlargement of the pancreatic duct and tumor size. $^{13}$

\section{Structural components in the association of type 2 diabetes and pancreatic carcinogenesis}

Fluctuations between hyperinsulinemia and hyperglycemia resulting in insulin resistance and chronic inflammation generate an environment driving the association between DM and PC. ${ }^{13}$ The determinants of the carcinogenic process include the initiation, promotion and progression stages of disease. ${ }^{13,35}$

Reactive oxygen species (ROS) are produced in excess in IR patients which can result in DNA damage and increase risk of mutagenesis and carcinogenesis. ${ }^{13,36}$ An excessive amount of ROS production can kill cancer cells, but the moderate concentrations stimulate tumor progression by promoting cell proliferation, survival, invasion and metastasis. ${ }^{32,37}$

Additionally, the risk of malignancy is high in case of insulin resistance caused by hyperinsulinemia. There are results that support the notion that obesity and insulin pathway play a direct role in PC. According to the connection between the results and the hypothesis, obesity causes increased insulin levels and the risk of hyperinsulinemia. Thus, insulin-like growth factor-binding proteins (IGFBPs) decrease, but circulating insulin-like growth factor 1 (IGF1) levels increase. ${ }^{20,38-40}$

Both insulin and IGF1 are promoters of cell proliferation and inhibition of apoptosis in tumor cells. ${ }^{20,38,41-43}$

It is proposed that the hyperinsulinemia effects on IGF-1 may contribute indirectly to tumor progression. The affinity for both the insulin receptor and IGF-1 receptor (IGF-1R) is the same for both insulin and
IGF-1. However, insulin's affinity for the insulin receptor is much greater than for IGF-1R. ${ }^{44}$ IGF-1 and IGF1R have powerful mitogenic and anti-apoptotic trends and hyperinsulinemia in an insulin resistant environment can strengthen this impact. The cancer-insulin hypothesis concludes that concentrations of IGFBP-1 and -2 are reduced because of chronic hyperinsulinemia. Therefore IGF-1 is present in the tissues increasing the risk of the development of cancer. An excessive expression of receptors for IGF-1 and insulin are seen in tumor cells, resulting in decreased hepatic production of IGFBP-1 and -2 and increased circulatory levels of active IGF-1. Therefore, there is an overall decrease in the growth stimulation cancer cells expressing these receptors. However, hyperinsulinemia resulting from IR can occur years before the diagnosis of diabetes. There are two possible pathways that can be activated after the insulin connection to its receptors: metabolic and mitogenic. ${ }^{13,35,44-47}$

\section{Metabolic pathway}

The phosphatidylinositol 3-kinase/AKT (PI3K/AKT) pathway is one in which are regulated glucose, protein, and lipid metabolism (Figure 1). ${ }^{48,49}$ Insulin binds to the insulin receptor and PI3K engages with the plasma membrane, it's phosphorylated and activated by the insulin receptor substrate (IRS) adapter proteins, there is an increased production of phosphatidylinositol-3,4,5triphosphate (PIP3), and the consequent activation of the 3 phosphoinositide-dependent protein kinase 1 (PDK1) and AKT. The $\mathrm{PI} 3 \mathrm{~K} / \mathrm{AKT}$ pathway is negatively regulated

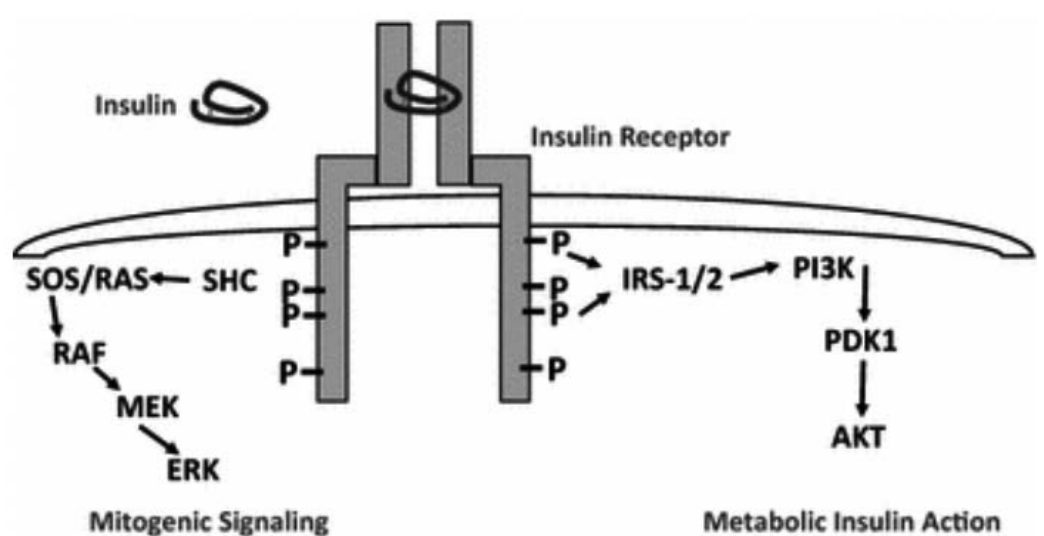

Figure 1. The metabolic pathway stimulated by the activated insulin receptors. Reprinted by permission from Springer Nature: Vigneri R, Goldfine ID, Frittitta L, Insulin, insulin receptors, and cancer. Journal of Endocrinological Investigation 2016;39(12). 
by the lipid phosphatase PTEN (phosphatase and tensin homolog encoded on chromosome 10 gene) that dephosphorylates PIP3. Other factors that play role in glucose uptake and translocation of glucose transporter 4 (GLUT4) to the plasma membrane (Rab GTPase-activating protein), glycogen synthesis (glycogen synthetase kinase 3, GSK3), transcription gene (forkhead box O transcription factors, FoxO), and ribosome biogenesis (tuberous sclerosis complex, TSC1 / TSC2 and mammalian target of rapamycin, $\mathrm{mTOR}$ ) are phosphorylated and activated by $\mathrm{AKT}^{48}$

\section{Mitogenic pathway}

The mitogenic pathway that causes cell proliferation is also stimulated by the activated insulin receptor. The RAS/RAF/mitogen-activated protein kinase kinase/extracellular signal-regulated kinases (RAS/RAF/MEK/ERK) cascade of the insulin receptor is activated by insulin. Then occurs the activation of GTPase Ras, and subsequently isoforms of RAF and MEK1/2 [mitogen-activated protein kinase kinases (MAPKKs)] and ERK1/2 mitogenactivated protein kinase (MAPKs). The cytosolic proteins are phosphorylated by ERK $1 / 2$, which would then migrate to the nucleus where they regulate gene expression and cell growth. The resultant effects depend on whether insulin that binds to the receptor-A or -B. Nonetheless, receptor A is responsible for the phosphorylation of intracellular substrates in response to insulin and IGF-2 with quantitative and temporal differences (Figure 2). ${ }^{48,50-53}$

\section{Effects of insulin resistance on metabolic and mitogenic pathways}

Insulin resistance (IR) inhibits the metabolic pathway. In this pathway, we see the increase in glucose transport into cells, stimulation of glycogen synthesis, and suppression of gluconeogenesis in the liver. On the other hand, IR does not inhibit the activity of the mitogenic pathway that leads to the proliferation of normal and tumor cells. When the hyperinsulinemia becomes chronic, it results in changes to IGFBP resulting in increased IGF-1 and -2 in tissues. Insulin is a mitogenic growth hormone and diabetes in association with tumor cells express receptors for insulin and IGF-1. Insulin suppresses IGFBP-1 resulting in elevated levels of IGF-1. ${ }^{13,54-57}$ IGF-1R and IGF-1 are expressed at high levels in PC cells. IGF-1mediated signal transduction reduces apoptosis in PC cells and stimulates the activation of intracellular signaling pathways such as RAS/RAF/MAPK and PI3K/AKT/ mammalian target of rapamycin (mTOR). Failure of downstream GLUT4 translocation is seen in IR. Insulin promotes cell growth and protein synthesis through the protein kinase B (PKB) and mTOR pathways, but the effects of the pathways are weaker than that of IGF-1. By abnormal phosphorylation of IRS-1, the metabolic pathway in hyperinsulinemia is debilitated. The expression of IRS-2 occurred for the phosphorylation of extracellular signal due to increase in activation of regulated kinase causes (ERK). MAPK remains intact because it belongs to the mitogenic pathway through RAS and mTOR. Mitogenic pathway with hyperinsulinism causes cell growth and survival. It is hypothesized that in the relationship between T2D and PC, IR and consequently hyperinsulinemia can support the growth of cancer cells. Visceral adiposity, inflammation, hyperglycemia and hyperinsulinemia increase IRS levels by stimulating the phosphorylation of RAS signaling proteins and the growth and proliferation of cancer cells. PI3K signaling in IRS association is inhibited by IR and the following GLUT4 translocation is interrupted.

The signal dysfunction causes involvement of the mitogenic pathway. Most tumor cells express insulin and IGF-1R. The insulin receptor stimulates tumor cell proliferation and metastasis. Glucose uptake is high in cancer cells, and insulin receptor does not play any role in glucose binding. This fact implies that activation of the insulin receptor may be in connection with mitogenesis and cell survival rather than with glucose reuptake. When IGF-1Rs interact with their ligands by phosphorylation of adapter proteins, multiple signaling pathways are activated. The initial kinase depends on the following signaling pathways. When these signaling pathways are activated it is the proliferation, protection from apoptosis, invasion and metastasis of cancer cells. ${ }^{13,46,58-63}$

\section{Effect of hyperglycemia on pancreatic cancer}

Presence of high levels of circulatory glucose can support the growth of malignant cells. Hyperglycemia is associated with increased formation of free radicals leading to the development of advanced glycation end products (AGEs). High HbA1c and hyperglycemic levels cause an increased risk of pancreatic cancer. It is thought that the metabolic pathways including the polyol pathway, glucose auto-oxidation, lipid peroxidation have inducing properties for the proliferation and mitogenesis. It is

\section{Different effects induced by Insulin or IGF-2 through the same Receptor (IR-A)}
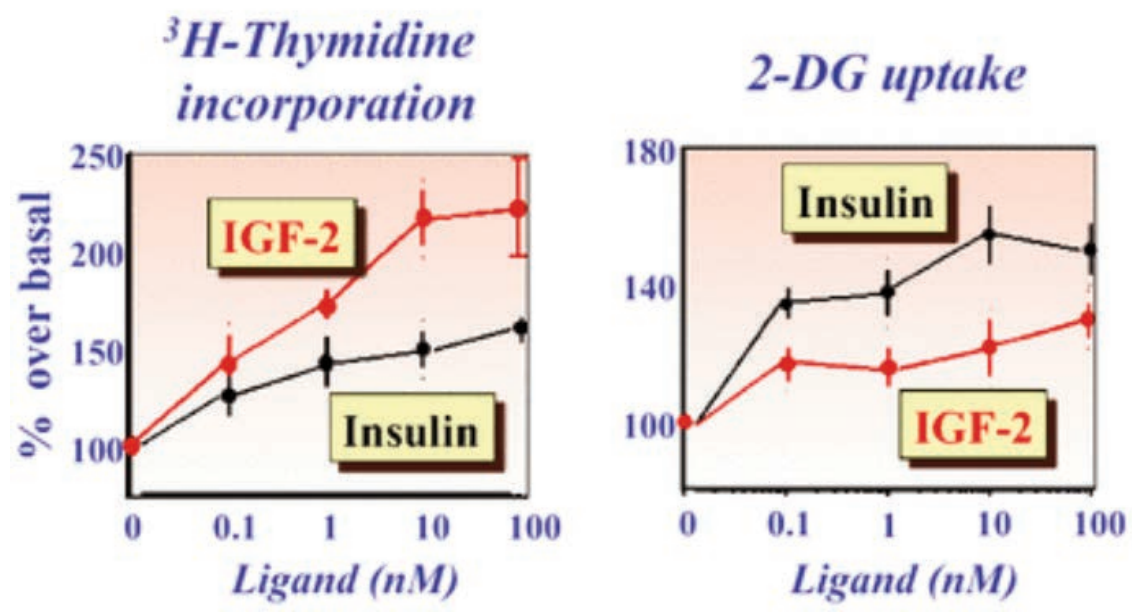

Figure 2. The mitogenic pathway that causes cell proliferation is stimulated by the activated insulin receptor. Reprinted by permission from Springer Nature: Vigneri R, Goldfine ID, Frittitta L, Insulin, insulin receptors, and cancer. Journal of Endocrinological Investigation 2016;39(12). 
believed that activation of these pathways are ROS dependent in the developement of PC. ${ }^{13,64-67}$

The pathogenesis of cancer metastasis is complex and not fully understood. In vitro studies have shown that the high glucose (HG) can accelerate and increase cell proliferation through increased epidermal growth factor (EGF) / EGFR signaling. ${ }^{32,34}$ Hyperglycemia may worsen the prognosis of the PC by increasing the migratory and invasive capacity through the production of hydrogen peroxide $\left(\mathrm{H}_{2} \mathrm{O}_{2}\right)$, which could be modulated by the expression of superoxide dismutase (SOD) through the activation of ERK and p38 MAPK that are signaling pathways. It has also been shown that DM increases perineural invasion in PC patients which aggravates the prognosis. ${ }^{32,68-70}$

Furthermore, EMT is formed during embryogenesis directing polarized epithelial cells to have a mesenchymal phenotype, and migratory and invasive greater capacity. ${ }^{32,33}$ EMT is characterized by reported decreases in E-cadherin cell-cell adhesion expression levels and detection of mesenchymal markers such as vimentin and $\mathrm{N}$-cadherin resulting in cell morphology changes as well as advanced cell motility. ${ }^{32,71}$ The production of $\mathrm{H}_{2} \mathrm{O}_{2}$ can support EMT in the developement of PC, with consequent increase of the motility and the invasion through the activation of the ERK signaling pathway. ${ }^{32,72}$ However, it still remains unclear if hyperglycemia might affect EMT PC. ${ }^{32}$

\section{Inflammation and pancreatic cancer}

Inflammatory cytokines, ROS, cyclooxygenase-2 (COX-2) and nuclear factor kappa B (NF-kB) are mediators of the inflammatory pathway. They are found to be in association with the expression of oncogenes, silencing of the tumor suppressor genes, and be involved to influence the cell cycle. ${ }^{13,73,74}$ All these can facilitate carcinogenesis of pancreas.

\section{Treatment options and survival}

Surgical resection is potentially the only treatment option. But this tumor has early local diffusion and metastases to distant organs. In the majority of patients clinical diagnosis is no longer possible to surgically resection. As a matter of fact, $80 \%$ of the patients are diagnosed locally advanced or metastasized. In these patients the disease shows a rapid progression and very few can live longer than a year. Even if the disease is localized during the diagnosis and radical surgical intervention is performed, the average survival rate is as short as 18 months ${ }^{2,75,76}$ with the 5-year rate less than $7 \% .{ }^{5,77}$ Despite the fact that the biology of PDAC is basically known, because of the absence of specific biomarker deficiency for early diagnosis, rapid local invasion and early metastases, limited proportion of patients undergoing surgical resection for treatment (15-20\%), and resistance to treatments such as chemotherapy, radiotherapy, molecular targeted therapy and immunotherapy, there has been no change in the survival period for the past thirty years, so new ways of treatment strategies should be sought. ${ }^{2}$

Pancreatic adenocarcinoma (PDAC) can metastasize to any organ. ${ }^{78-84}$ These metastases occur via hematogenous, lymphogenic and perineural or directly intracavitary distribution. ${ }^{78-80}$

After resection for PDAC, recurrence of disease first manifests itself as pulmonary metastases. These metastases are identified as oligometastases, isolated multiple metastases, or metastatic metastases to other organs. The prognosis of metachronous lung metastases after resection is better than other metastatic diseases. ${ }^{78}$

Studies using genetically engineered mouse models have also provided important information about the onset and progression of pancreatic cancer, as well as the prevention and treatment. ${ }^{5,85}$ Oncogenic Krasmediated and cerulein-induced mouse model of chronic pancreatitis in LSLKrasG12D; Pdx1-Cre (KC) mice, as well as LSL-KrasG12D/+; Trp53fl / +; Pdx1-Cre (KPC) were used to investigate the preventive and therapeutic effects of metformin. A delayed formation of precursor lesions and impaired tumor progression were observed following metformin treatment. It is known that oncogenic Kras-mediated PDAC mouse models recapitulate tumor onset and progression from ADM to mPanINs and eventually to invasive pancreatic cancer. Metformin intake led to delayed pancreatic tumorigenesis in the KC mouse model, represented by a low percentage of early lesions [ADM and murine pancreatic intraepithelial neoplasia1(mPanIN1)] and late mPanIN lesions (mPanIN2 and mPanIN3). ${ }^{5}$

\section{Conclusions}

The relationship between diabetes and the PC is very complex. Previously, some epidemiological studies reported that it is not possible for long-standing DM to be a risk factor for PC. However, the more recent studies examining the onset of DM suggest its contribution to carcinogenesis.

It has also been shown that long-lasting diabetes is a causal factor for $\mathrm{PC}$, and the onset of diabetes is its revelation. Therefore, the relationship between the two are not yet clear. It has been shown that the duration of diabetes resulting in an environment dominated by factors such as hyperinsulinemia, IR, high levels of circulating IGFs, hyperglycemia, and chronic inflammation are responsible of metabolic link between the diseases driving the consequent state of pancreatic carcinogenesis. However, the results from animal experiments seem promising in terms of treatment.

\section{References}

1. Longnecker DS. Anatomy and Histology of the Pancreas. Pancreapedia: Exocrine Pancreas Knowledge Base 2014.

2. Pelosi E, Castelli G, Testa U. Pancreatic cancer: molecular characterization, clonal evolution and cancer stem cells. Biomedicines 2017;5:E65.

3. Sethi V, Giri B, Saluja A, et al. Insights into the pathogenesis of pancreatic cystic neoplasms. Dig Dis Sci 2017;62:1778-86.

4. Hruban RH, Maitra A, Kern SE, et al. Precursors to pancreatic cancer. Gastroenterol Clin N Am 2007;36:83151.

5. Chen K, Qian W, Jiang Z, et al. Metformin suppresses cancer initiation and progression in genetic mouse models of pancreatic cancer. Mol Cancer 2017;16:131.

6. Basturk O, Hong SM, Wood LD, et al. A revised classification system and recommendations from the Baltimore consensus meeting for neoplastic precursor lesions in the pancreas. Am J Surg Pathol 2015;39:1730-41.

7. Sousa CM, Biancur DE, Wang X, et al. Pancreartic stellate cells support tumor metabolism through autophagic alanine secretion. Nature 2016;536:479-83.

8. Giovannucci E, Harlan DM, Archer $\mathrm{MC}$, et al. Diabetes and cancer: a consensus report. Diabetes Care 2010;33: 1674-85.

9. Shen H, Zhan M, Wang W, et al. Impact of diabetes mellitus on the survival of pancreatic cancer: a meta-analysis. Onco Targets Ther 2016;9:1679-88.

10. Sen S, He Y, Koya D, et al. Cancer biology in diabetes. J Diabetes Investig 
2014;5:251-64.

11. Whiting DR, Guariguata L, Weil C, et al. IDF diabetes atlas: global estimates of the prevalence of diabetes for 2011 and 2030. Diabetes Res Clin Pract 2011;94:311-21.

12. American Diabetes Association. Diagnosis and classification of diabetes mellitus. Diabetes Care 2010;33:S62S69.

13. Biadgo B, Abebe M. Type 2 diabetes mellitus and 1ts association with the risk of pancreatic carcinogenesis: a review. Korean J Gastroenterol 2016;67:16877.

14. McAuliffe JC, Christein JD. Type 2 diabetes mellitus and pancreatic cancer. Surg Clin North Am 2013;93:619-27.

15. Hine RJ, Srivastava S, Milner JA, et al. Nutritional links to plausible mechanisms underlying pancreatic cancer: a conference report. Pancreas 2003;27:356-66.

16. Rahib L, Smith BD, Aizenberg R, et al. Projecting cancer incidence and deaths to 2030: The unexpected burden of thyroid, liver and pancreas cancers in United States. Cancer Res 2014;74:2913-21.

17. Xu JB, Jiang B, Chen Y, et al. Optimal adjuvant chemotherapy for resected pancreatic adenocarcinoma: a systematic review and network meta-analysis. Oncotarget 2017;8:81419-29.

18. Siegel R, Naishadham D, Jemal A. Cancer Statistics, 2012. CA Cancer J Clin 2012;62:10-29.

19. Mehta KY, Wu HJ, Menon SS, et al. Metabolomic biomarkers of pancreatic cancer: a meta-analysis study. Oncotarget 2017;8:68899-915.

20. Carreras-Torres R, Johansson M, V, et al. The role of obesity, type 2 diabetes, and metabolic factors in pancreatic cancer: a mendelian randomization study. J Natl Cancer Inst 2017;109.

21. Renehan AG, Tyson M, Egger M, et al. Body-mass index and incidence of cancer: A systematic review and metaanalysis of prospective observational studies. Lancet 2008;371:569-78.

22. Aune D, Greenwood DC, Chan DSM, et al. Body mass index, abdominal fatness and pancreatic cancer risk: A systematic review and non-linear dose - response meta-analysis of prospective studies. Ann Oncol 2012;23:843-52.

23. Urayama KY, Holcatova I, Janout V, et al. Body mass index and body size in early adulthood and risk case - control study. Int J Cancer 2011;129:2875-84.

24. Aune D, Rita A, Doris V, et al. Height and pancreatic cancer risk: A systematic review and meta-analysis of cohort stu- dies. Cancer Causes Control

2012;23:1213-22.

25. Chen H, Qin S, Wang $M$, et al. Association between cholesterol intake and pancreatic cancer risk: Evidence from a meta-analysis. Sci Rep 2015;5:8243-48.

26. Liao WC, Tu YK, Wu MS, et al. Blood glucose concentration and risk of pancreatic cancer: Systematic review and dose-response meta-analysis. BMJ 2015;350:g7371.

27. Pisani P. Hyper-insulinaemia and cancer, meta-analyses of epidemiological studies. Arch Physiol Biochem 2008;114:63-70.

28. Elena JW, Steplowski E, Yu K, et al. Diabetes and risk of pancreatic cancer: A pooled analysis from the pancreatic cancer cohort consortium. Cancer causes Control 2013;24:13-25.

29. Huxley R, Ansary-Moghaddam A, Berrington de González A, et al. Type-II diabetes and pancreatic cancer: A metaanalysis of 36 studies. Br J Cancer 2005;92:2076-83.

30. Rahn S, Zimmermann V, Viol F, et al. Diabetes as risk factor for pancreatic cancer: Hyperglycemia promotes epithelial-mesenchymal-transition and stem cell properties in pancreatic ductal epithelial cells. Cancer Lett 2017;415:12950.

31. Szablewski L. Diabetes mellitus: influences on cancer risk. Diabetes Metab Res Rev 2014;30:543-53.

32. Li W, Zhang L, Chen $\mathrm{X}$, et al. Hyperglycemia Promotes the Epithelial-Mesenchymal Transition of Pancreatic Cancer via Hydrogen Peroxide. Oxid Med Cell Longev 2016;2016:5190314.

33. Li W, Ma Q, Liu J, et al. Hyperglycemia as a mechanism of pancreatic cancer metastasis. Frontiers Biosci 2012;17:1761-74.

34. Stolzenberg-Solomon RZ, Graubard BI, Chari S, et al. Insulin, glucose, insulin resistance, and pancreatic cancer in male smokers. JAMA 2005;294:28728.

35. Giovannucci E, Harlan DM, Archer $\mathrm{MC}$, et al. Diabetes and cancer: a consensus report. CA Cancer J Clin 2010;60:207-21.

36. Ciaraldi TP, Sasaoka T. Review on the in vitro interaction of insulin glargine with the insulin/insulin-like growth factor system: potential implications for metabolic and mitogenic activities. Horm Metab Res 2011;43:1-10.

37. Nishikawa M, Hashida M, Takakura Y. Catalase delivery for inhibiting ROSmediated tissue injury and tumor metas- tasis. Adv Drug Deliv Rev 2009;61:319-26.

38. Braun S, Bitton-Worms K, Leroith D. The link between the metabolic syndrome and cancer. Int J Biol Sci 2011;7: 1003-15.

39. Kahn BB, Flier JS. Obesity and insulin resistance. J Clin Invest 2000;106:47381.

40. Renehan AG, Zwahlen M, Egger M. Adiposity and cancer risk: New mechanistic insights from epidemiology. Nat Rev Cancer 2015;15:484-98.

41. Esposito K, Chiodini P, Colao A, et al. Metabolic syndrome and risk of cancer: A systematic review and meta-analysis. Diabetes Care 2012;35:2402-11.

42. Hezel AF, Kimmelman AC, Stanger BZ, et al. Genetics and biology of pancreatic ductal adenocarcinoma. Genes Dev 2006;20:1218-49.

43. Pothiwala P, Jain SK, Yaturu S. Metabolic syndrome and cancer. Metab Syndr Relat Disord 2009;7:279-88.

44. Vigneri P, Frasca F, Sciacca L, et al. Diabetes and cancer. Endocrine Related Cancer 2009;16:1103-23.

45. Batty GD, Shipley MJ, Marmot M, et al. Diabetes status and post-load plasma glucose concentration in relation to sitespecific cancer mortality: findings from the original Whitehall study. Cancer Causes Control 2004;15:873-81.

46. Pollak M. Insulin and insulin-like growth factor signalling in neoplasia. Nat Rev Cancer 2008;8:915-28.

47. Muntoni S, Muntoni S. Insulin resistance: pathophysiology and rationale for treatment. Ann Nutr Metab 2011;58:2536.

48. Vigneri R, Goldfine ID, Frittitta L. Insulin, insulin receptors, and cancer. J Endocrinol Invest 2016;39:1365-76.

49. White MF. The IRS-signalling system: a network of docking proteins that mediate insulin action. Mol Cell Biochem 1998;182:3-11.

50. Taniguchi CM, Emanuelli B, Kahn CR. Critical nodes in signalling pathways: insights into insulin action. Nat Rev Mol Cell Biol 2006;7:85-96.

51. Ward CW, Lawrence MC. Ligand-induced activation of the insulin receptor: a multi-step process involving structural changes in both the ligand and the receptor. BioEssays 2009;31:422-34.

52. Belfiore A. The role of insulin receptor isoforms and hybrid insulin/IGF-I receptors in human cancer. Curr Pharm Des 2007;13:671-86.

53. Belfiore A, Frasca F, Pandini G, et al. Insulin receptor isoforms and insulin receptor/insulin-like growth factor receptor hybrids in physiology and 
disease. Endocr Rev 2009;30:586-623.

54. Boden G. Obesity, insulin resistance and free fatty acids. Curr Opin Endocrinol Diabetes Obes 2011;18:139-43.

55. Renehan AG, Zwahlen M, Minder C, et al. Insulin-like growth factor (IGF)-I, IGF binding protein-3, and cancer risk: systematic review and meta-regression analysis. Lancet 2004;363:1346-53.

56. Goodwin PJ. Insulin in the adjuvant breast cancer setting: a novel therapeutic target for lifestyle and pharmacologic interventions? J Clin Oncol 2008;26:833-4.

57. Conover CA, Lee PD, Kanaley JA, et al. Insulin regulation of insulin-like growth factor binding protein-1 in obese and nonobese humans. J Clin Endocrinol Metab 1992;74:1355-60.

58. Cusi K, Maezono K, Osman A, et al. Insulin resistance differentially affects the PI 3-kinase- and MAP kinasemediated signaling in human muscle. $\mathrm{J}$ Clin Invest 2000;105:311-20.

59. Dann SG, Selvaraj A, Thomas G. mTOR Complex1-S6K1 signaling: at the crossroads of obesity, diabetes and cancer. Trends Mol Med 2007;13:2529.

60. Sun G, Kashyap SR. Cancer risk in type 2 diabetes mellitus: metabolic links and therapeutic considerations. J Nutr Metab 2011; 2011:708183.

61. Zhang H, Pelzer AM, Kiang DT, et al. Down-regulation of type I insulin-like growth factor receptor increases sensitivity of breast cancer cells to insulin. Cancer Res 2007;67:391-7.

62. Mardilovich K, Pankratz SL, Shaw LM. Expression and function of the insulin receptor substrate proteins in cancer. Cell Commun Signal 2009;7:14.

63. Clemmons DR, Maile LA, Ling Y, et al. Role of the integrin alphaVbeta3 in mediating increased smooth muscle cell responsiveness to IGF-I in response to hyperglycemic stress. Growth Horm IGF Res 2007;17:265-70.

64. Yamasaki K, Hayashi Y, Okamoto S, et al. Insulin-independent promotion of chemically induced hepatocellular tumor development in genetically dia- betic mice. Cancer Sci 2010;101:65-72.

65. Grote VA, Rohrmann S, Nieters A, et al. Diabetes mellitus, glycated haemoglobin and C-peptide levels in relation to pancreatic cancer risk: a study within the European Prospective Investigation into Cancer and Nutrition (EPIC) cohort. Diabetologia 2011;54:3037-46.

66. Welsch T, Kleeff J, Seitz HK, et al. Update on pancreatic cancer and alcohol-associated risk. J Gastroenterol Hepatol 2006;21:S69-S75.

67. Brownlee M. Biochemistry and molecular cell biology of diabetic complications. Nature 2001;414:813-20.

68. Li W, Ma Q, Li J, et al. Hyperglycemia enhances the invasive and migratory activity of pancreatic cancer cells via hydrogen peroxide. Oncol Rep 2011;25:1279-87.

69. Li W, Ma Z, Ma J, et al. Hydrogen peroxide mediates hyperglycemia-induced invasive activity via ERK and p38 MAPK in human pancreatic cancer. Oncotarget 2015;6:31119-33.

70. Chari ST, Leibson CL, Rabe KG, et al. Pancreatic cancer-associated diabetes mellitus: prevalence and temporal association with diagnosis of cancer. Gastroenterology 2008;134:95-101.

71. Yilmaz M, Christofori G. Mechanisms of motility in metastasizing cells. Mol Cancer Res 2010;8:629-42.

72. Li W, Cao L, Han L, et al. Superoxide dismutase promotes the epithelialmesenchymal transition of pancreatic cancer cells via activation of the $\mathrm{H} 2 \mathrm{O} 2 / \mathrm{ERK} / \mathrm{NF}-\kappa \mathrm{B}$ axis. Int $\mathrm{J}$ Oncol 2015;46:2613-20.

73. Sindhu RK, Koo JR, Roberts CK, et al. Dysregulation of hepatic superoxide dismutase, catalase and glutathione peroxidase in diabetes: response to insulin and antioxidant therapies. Clin Exp Hypertens 2004;26:43-53.

74. Defronzo RA. Banting lecture. From the triumvirate to the ominous octet: a new paradigm for the treatment of type 2 diabetes mellitus. Diabetes 2009;58:773-95.

75. Kleef J, Korc M, Apte M, et al. Pancreatic cancer. Nat Rev Dis Primers 2016;2:16022.
76. Rebelo A, Molpeceres J, Rijo P, et al. Pancreatic cancer therapy review: From classic therapeutic agents to modern nanotechnologies. Curr Drug Met 2017;18:346-59.

77. Siegel RL, Miller KD, Jemal A. Cancer statistics, 2016. CA Cancer J Clin 2016;66:7-30.

78. Lovecek M, Skalicky P, Chudacek J, et al. Different clinical presentations of metachronous pulmonary metastases after resection of pancreatic ductal adenocarcinoma: Retrospective study and review of the literature. World $\mathrm{J}$ Gastroenterol 2017;23:6420-8.

79. Kamisawa $T$, Isawa $T$, Koike $M$, et al. Hematogenous metastases of pancreatic ductal carcinoma. Pancreas 1995; 11:345-9.

80. Lu F, Poruk KE, Weiss MJ. Surgery for oligometastasis of pancreatic cancer. Chin J Cancer Res 2015;27:358-67.

81. Yachida S, Iacobuzio-Donahue CA. The pathology and genetics of metastatic pancreatic cancer. Arch Pathol Lab Med 2009; 133:413-22.

82. Embuscado EE, Laheru D, Ricci F, et al. Immortalizing the complexity of cancer metastasis: genetic features of lethal metastatic pancreatic cancer obtained from rapid autopsy. Cancer Biol Ther 2005;4:548-54.

83. Disibio G, French SW. Metastatic patterns of cancers: results from a large autopsy study. Arch Pathol Lab Med 2008;132:931-9.

84. Mao C, Domenico DR, Kim K, et al. Observations on the developmental patterns and the consequences of pancreatic exocrine adenocarcinoma. Findings of 154 autopsies. Arch Surg 1995;130: 125-34.

85. Lee JW, Komar CA, Bengsch F, et al. Genetically engineered mouse models of pancreatic cancer: The KPC Model (LSL-Kras(G12D/+) ;LSL-

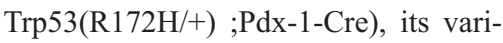
ants, and their application in immunooncology drug discovery. Curr Protoc Pharmacol 2016;73:14-39. 